\title{
Distributions of three species of Nihonotrypaea (Decapoda: Thalassinidea: Callianassidae) in intertidal habitats along an estuary to open-sea gradient in western Kyushu, Japan
}

Akio Tamaki, Jun-Ichi Itoh, and Kumiko Kubo

\begin{abstract}
The intertidal distributions and habitats of three congeneric callianassid shrimps [Nihonotrypaea harmandi (Bouvier), N. japonica
\end{abstract} (Ortmann), and $N$. petalura (Stimpson)] were surveyed along the estuary to opensea gradient from Ariake Sound through Tachibana Bay to the East China Sea in western Kyushu, Japan. In the light of long-term-averaged salinity (psu) values in the surface waters (at $5 \mathrm{~m}$ depth) in the rainy season, ( $N$. harmandi $+N$. petalura) and $N$. japonica mainly occurred in the ranges of 34.0-30.5 (the East China Sea + Tachibana Bay + the outermost part of Ariake Sound) and 30.5-28.5 (the middle part of Ariake Sound), respectively, with their distribution boundary distinct. Using the Venice-system terms for the classification of brackish waters, the former species group could be designated as euhaline to mixo-euhaline species, while the latter species as a mixo-polyhaline species. From the viewpoint of the substrate conditions and their dimensions, the habitats for the three species were basically characterized, as follows: 1) $\mathrm{N}$. harmandi - the relatively small sandflats and sandy beaches of medium - fine sands, with boulder beaches, very exposed sandy beaches, and mudflats uninhabited; 2) N. petalura - small sand patches surrounded by boulders in boulder beaches; and 3) N. japonica - the extensive sandflats of medium - fine sands, with boulder beaches, exposed sandy beaches, and mudflats uninhabited.

\section{Introduction}

One of the major gradients in the shore environment is the marine-freshwater gradient of salinity, and a multitude of species distribution patterns along this gradient have been recorded (Raffaelli \& Hawkins, 1996). Callianassid ghost shrimps are one of the most common macro-invertebrates worldwide, occurring from marine to estuarine intertidal sediments. The first author (AT) and his colleagues have studied the benthic population dynamics of a callianassid species identified as Callianassa japonica Ortmann on an intertidal sandflat of an estuarine system in western Kyushu, Japan (e.g., Tamaki et al., 1997). Until recently, it was believed that two species of Callianassa occurred in Japan: $C$. japonica Ortmann and C. petalura Stimpson (see Sakai, 1969). However, in their taxonomic revision of the Japanese species, Manning \& Tamaki (1998) revealed that Sakai's 'C. japonica' was in fact a mixture of $C$. japonica and $C$. harmandi Bouvier. They also proposed a new genus, Nihonotrypaea, to include the three Japanese species. Now all the material studied by AT and his colleagues has proven to be $N$. harmandi (Bouvier), exclusively occurring in their main study site [ = the Tomioka Bay sandflat (Figs. 2 and 8)]. It has been confirmed that both $N$. harmandi and $N$. japonica (Ortmann) inhabit bare intertidal sandflats (e.g., Tamaki \& Ueno, 1998), and it is now 


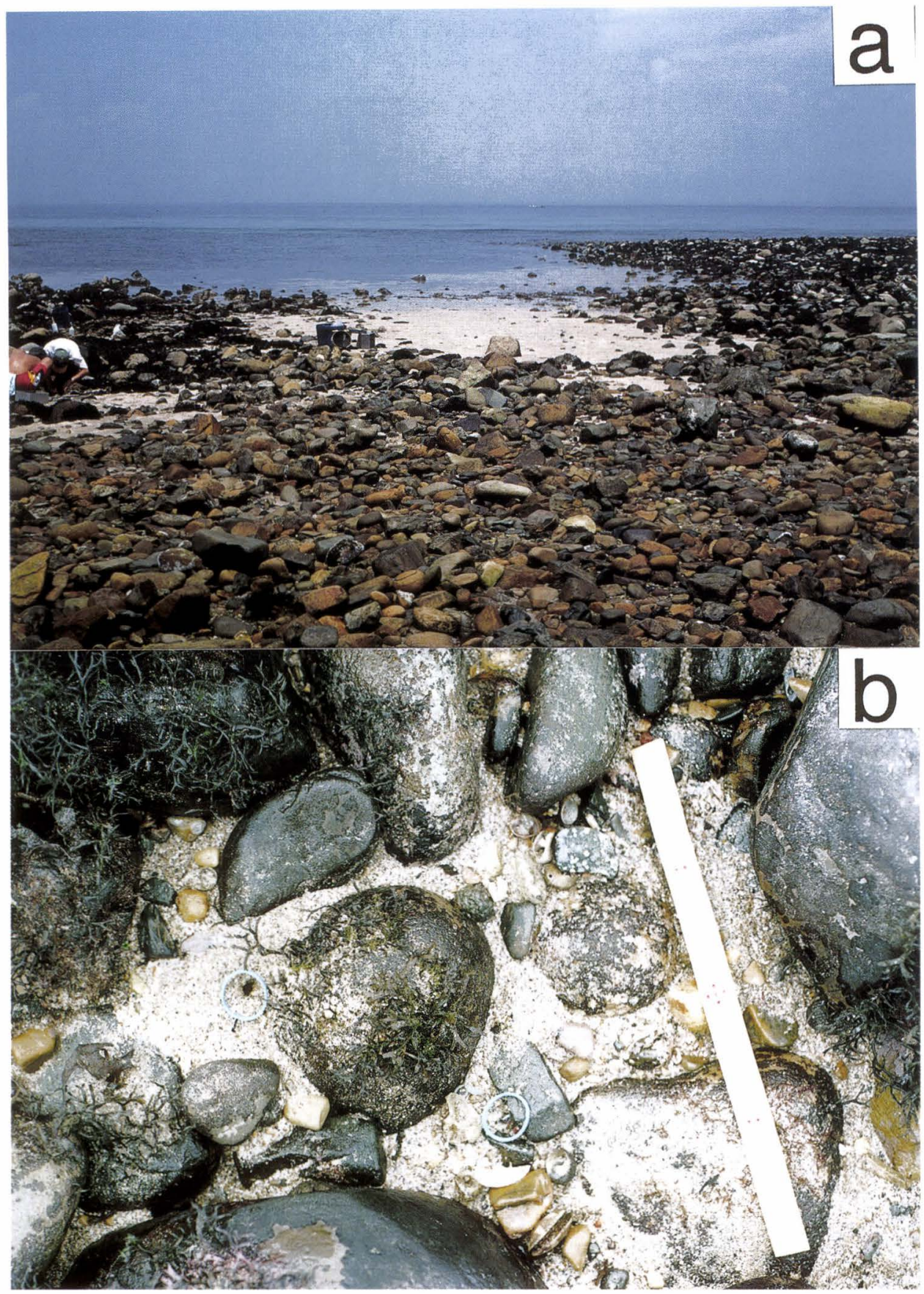

Fig. 1. Typical boulder zone inhabited by Nihonotrypaea petalura (Stn $\mathrm{j}$ in Fig. 8) (a) and sand patches among boulders, with two shrimp burrow-openings circled by the small rubber bands (b). The full range of the scale in (b) is $20 \mathrm{~cm}$. 
known that $N$. petalura (Stimpson) inhabits small sand patches surrounded by boulders on intertidal boulder beaches such as shown in Fig. 1 (e.g., Konishi et al., 1990). However, any larger-scale distribution ranges for the three Nihonotrypaea species along an estuary to opensea gradient have not been investigated. Recently we have extensively surveyed the distribution of the three species in intertidal habitats of an estuarine system in western Kyushu, including the Tomioka Bay sandflat. The present paper reports both the segregation of the distributions for the three species and their habitat characteristics in terms of substrate grain-size compositions.

\section{Materials and Methods}

Characteristics of the waters of the study area

The study area is located in the middle part of western Kyushu, Japan (around $130^{\circ} \mathrm{E}$ and $32.5^{\circ} \mathrm{N}$ ), where there are two major estuaries, Ariake Sound and Yatsushiro Sound (called Ariake-Kai and Yatsushiro-Kai in Japanese) (Fig. 2). The two sounds are separated by both Uto Peninsula projecting from the mainland of Kyushu and three large islands (Ôyano-, Amakusa-Kamishima-, and Amakusa-Shimoshima-Islands). Ariake Sound, covering an area of $1700 \mathrm{~km}^{2}$, connects with the outer westward waters, Tachibana Bay, through a narrow $5 \mathrm{~km}$ wide inlet (Hayasaki Inlet) located between Shimabara Peninsula and Amakusa-Shimoshima Island. The tidal current velocities at the inlet reach as high as 7 knots at spring tides. Tachibana Bay, covering an area of $700 \mathrm{~km}^{2}$, is open westwardly to the East China Sea (open sea). Tomioka Bay (Stn 35 in Fig. 8) is a small part of Tachibana Bay, situated at the northwestern corner of AmakusaShimoshima Island. The waters from Ariake Sound to the East China Sea forms one of the most peculiar estuarine

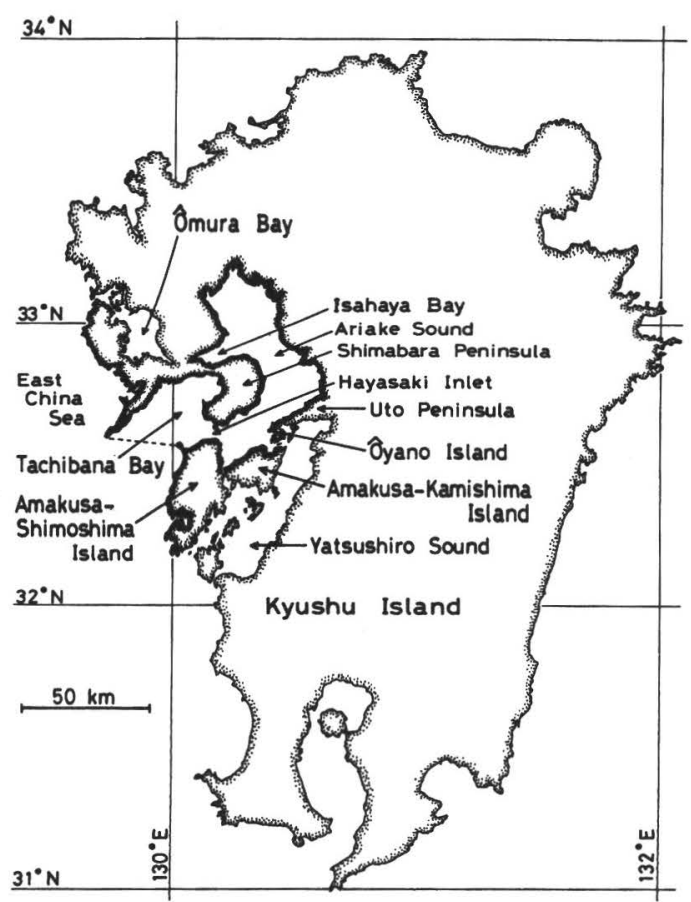

Fig. 2. Location of the study area including Ariake Sound, Tachibana Bay, and the East China Sea in western Kyushu, Japan. The western limit of Tachibana Bay is designated by the broken line. Tomioka Bay, a small part of Tachibana Bay, is situated at the northwestern corner of Amakusa-Shimoshima Island (= Stn 35 in Fig. 8). The target coastline for the survey of the distributions of the three Nihonotrypaea species is indicated by the thick line.

systems in Japan. The target coastline for this study is indicated by the thick line in Fig. 2. Thus this study encompasses the entire gradient from the estuary to the open sea.

Various characteristics of the waters related to this study have been compiled in the literature, as follows: 1) Ariake Sound -Nagasaki Prefectural Institute of Fisheries (hereafter abbreviated as NPIF) (1956) and one chapter of the book, 'Coastal Oceanography of Japanese Islands' [Chapter 21 in Coastal Oceanography Research Committee, The Oceanographical Society of Japan (hereafter ab- 

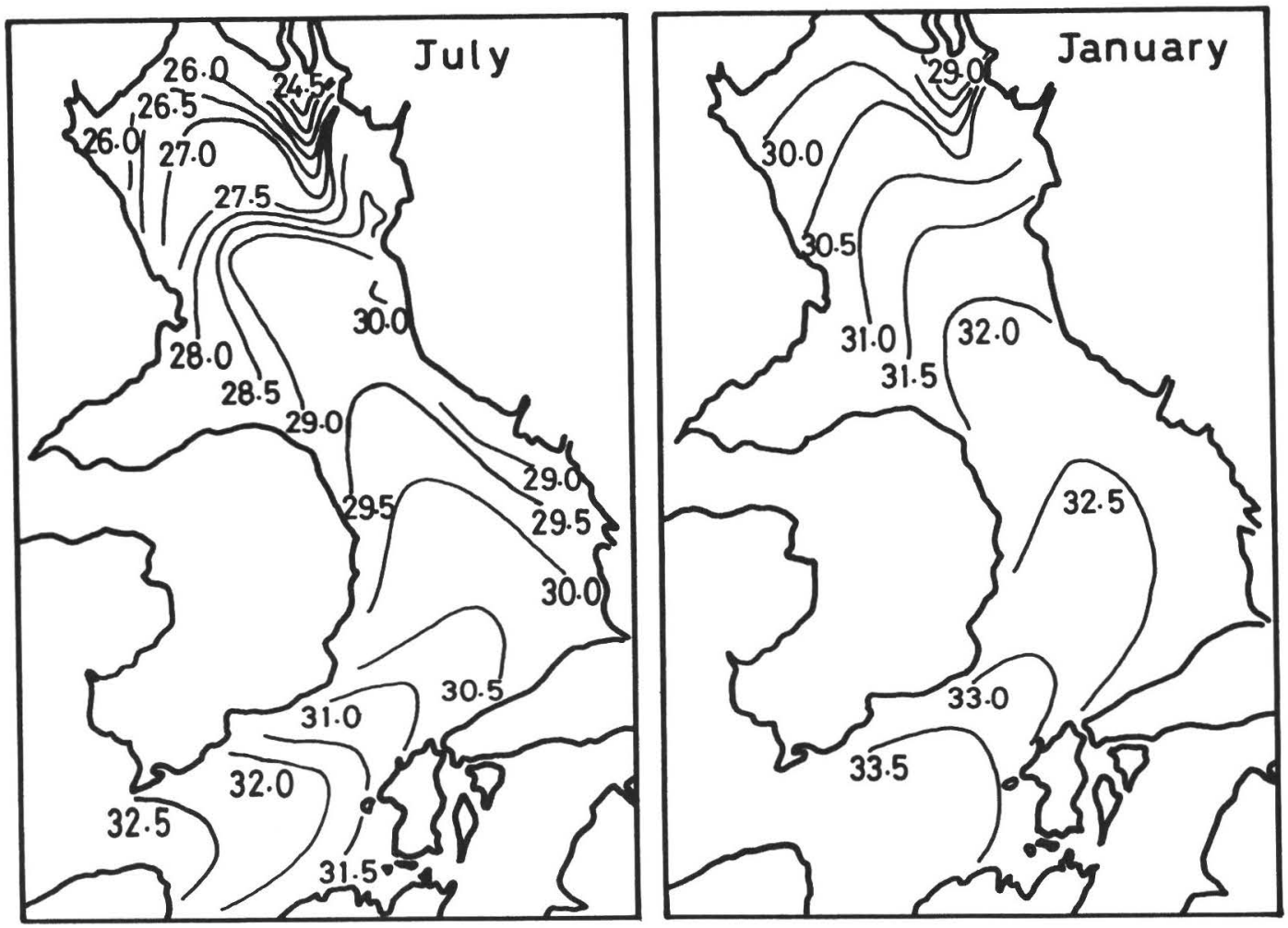

Fig. 3. Isohalines (psu) at $5 \mathrm{~m}$ depth of Ariake Sound in July and January, averaged over 10 years from 1972 to 1981. Adapted from Figs. 12 and 13 of Part II of Chapter 21 in CORC, OSJ (1985), with the permission of the publisher.

breviated as CORC, OSJ) (1985)]; 2) the East China Sea near the coast of western Kyushu (hereafter simply referred to as the East China Sea) - one chapter of a supplementary book of the above [Chapter 33 in CORC, OSJ (1990)]; and 3) Tachibana Bay - Seikai National Fisheries Research Institute (hereafter abbreviated as SNFRI) (1970) and Matsuno et al. (1999). Using these references, we summarize the essential information on the water characteristics of the study area in the following paragraphs.

Ariake Sound is largely shallow (average, $20 \mathrm{~m}$ ), though the deepest part (caldron) located $17 \mathrm{~km}$ east of Hayasaki Inlet measures about $160 \mathrm{~m}$. It is estimated that $99.5 \%$ of water exchange between Ariake Sound and the outside seas is made between Tachibana Bay via
Hayasaki Inlet, with the remainder being between Yatsushiro Sound. The deepest part of Tachibana Bay (caldron, about 100 $\mathrm{m}$ deep) is located $7 \mathrm{~km}$ west of Hayasaki Inlet. The depth of the deepest part of the western limit of the bay is about $80 \mathrm{~m}$.

The largest rivers responsible for the estuarine conditions of Ariake Sound are located on the northern and eastern coasts (see Fig. 7). Of these rivers the Chikugo River and the Midori River entering the northeastern corner of the sound and the base of Uto Peninsula, respectively, together comprise about $60 \%$ of the freshwater supply to the sound. The smaller rivers enter the other coast of the sound (except for a larger river at the westernmost Isahaya Bay) and the coasts along Tachibana Bay and the East China Sea. Since Japan is under a monsoon cli- 

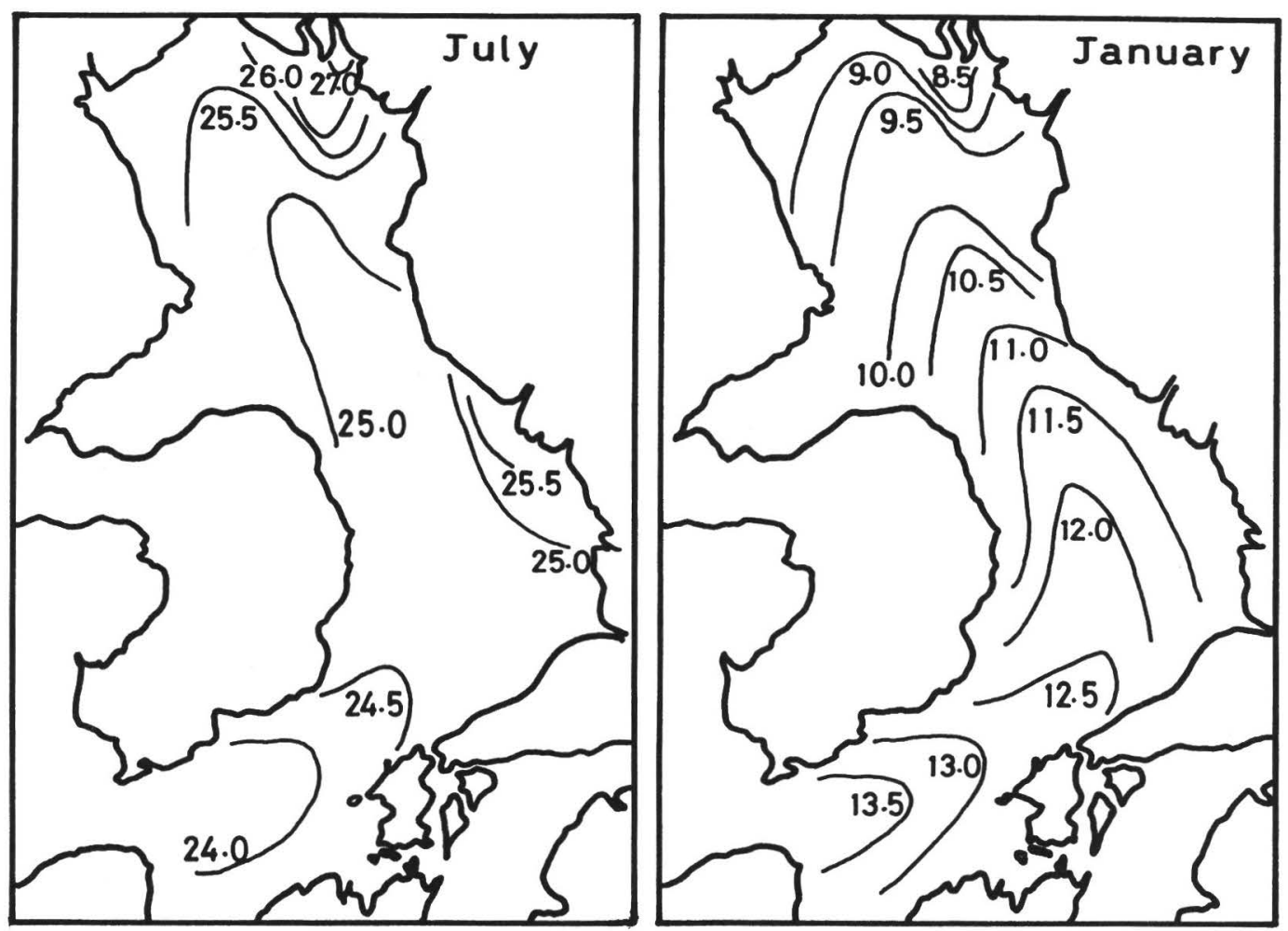

Fig. 4. Isotherms $\left({ }^{\circ} \mathrm{C}\right)$ at $5 \mathrm{~m}$ depth of Ariake Sound in July and January, averaged over 10 years from 1972 to 1981. Adapted from Figs. 6 and 7 of Part II of Chapter 21 in CORC, OSJ (1985), with the permission of the publisher.

matic regime, salinity of the Ariake Sound waters is lowest during June and July due to the heaviest seasonal rainfall. The reproductive activities of the three Nihonotrypaea species are at their maxima in the rainy season (Tamaki et al., 1997, unpublished). By contrast, in winter, which is the driest season, the sound waters are most affected by those originating from the East China Sea. The isohalines at $5 \mathrm{~m}$ depth of Ariake Sound in July and January, averaged over 10 years from 1972 to 1981, are shown in Fig. 3. From Hayasaki Inlet, salinity (psu) declines from 32.5 to 24.5 in July and from 33.5 to 29.0 in January. The temporal variation in salinity is greater, especially in the inner part of the sound during the rainy season. For example, around the northernmost distribution limit of $N$. japonica (Stn 18 in Fig. 8), the salinity values during July range from 15 to 28 . Salinity at $5 \mathrm{~m}$ depth of the East China Sea, averaged over 24 years from 1963 to 1986, ranges from 33.6 to 34.0 in July and is 34.6 in January. The salinity values in Tachibana Bay are intermediate; there are two major water masses in Tachibana Bay, the northern lower-salinity water mass and the southern higher-salinity water mass, with an estuarine front often formed between them. The two water masses are generated originally from the Ariake Sound waters and the East China Sea waters, respectively, with their timeaveraged current directions being opposite (westward and eastward).

The isotherms at $5 \mathrm{~m}$ depth of Ariake Sound in July and January (the data source as mentioned in the above para- 


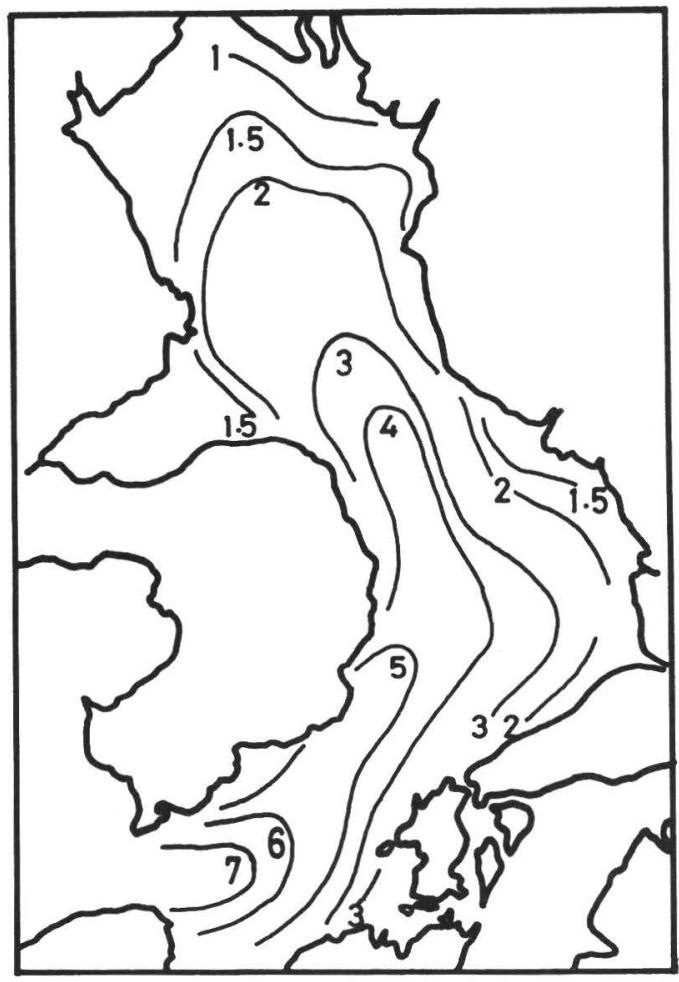

Fig. 5. Isopleths of transparency (m) of the waters in Ariake Sound in July, averaged over 10 years from 1972 to 1981 . Adapted from Fig. 15 of Part II of Chapter 21 in CORC, OSJ (1985), with the permission of the publisher.

graph) are shown in Fig. 4. The seasonal variation in the water temperature is greater in the more interior part of the sound, with higher values in July and lower values in January; for example, between 27.0 and $8.5^{\circ} \mathrm{C}$ in the innermost part, and between 24.0 and $13.5^{\circ} \mathrm{C}$ near Hayasaki Inlet. The water temperature at $5 \mathrm{~m}$ depth of the East China Sea (the data source as above) increases from 23 to $26^{\circ} \mathrm{C}$ during July (based on records every 3 days) and drops from 17 to $16^{\circ} \mathrm{C}$ during January. In short, the above spatial and temporal variations in both salinity and water temperature from Ariake Sound to the East China Sea are typical of estuary to open-sea gradients.

Figure 5 shows the isopleths of trans- parency of the waters in Ariake Sound in July (averaged data as in Figs. 3 and 4) (CORC, OSJ, 1985). The transparency is highest near Hayasaki Inlet, and decreases up the sound. The distribution pattern of the isopleths is similar to that of isohalines (Fig. 3). This is understandable by the fact that in Ariake Sound, turbidity of the water column is caused by riverine fine loads and resuspended particles from the extensive intertidal flats, especially from the innermost mudflats (see the next section) (CORC, OSJ, 1985).

A summary of the subdivision of the Ariake Sound waters, which is a scheme presented by NPIF (1956), divides the waters from Hayasaki Inlet into three water regimes named Area-A, -B, and -C (Fig. 6). Area A, designated originally as 'the open-sea water regime,' is least amenable to the weather conditions, with the higher salinities and lower temperatures in summer and the higher salinities and higher temperatures in winter. By contrast, Area C ('the coastal-water regime') is most strongly affected by both the weather and climatic conditions and receives more freshwater. In Area B ('the mixed-water regime'), the surface and bottom layers are influenced by the Area$\mathrm{C}$ and Area-A waters, respectively.

\section{Characteristics of intertidal substrates of} the study area

The coast of western Kyushu is under a semi-diurnal tidal regime. The tidal range occurring in Ariake Sound is the largest in the Japanese waters. The averaged figure for the spring tides along the coastline from the East China Sea through Tachibana Bay to around Hayasaki Inlet is about $3 \mathrm{~m}$, from which it becomes amplified interiorly to reach about $6 \mathrm{~m}$ in the innermost part of Ariake Sound. In the sound, as a result of the interactions between the four main factors [1) the large tidal excursions, 2) the river discharges forming deltas, 3) the averaged seawater circulation pattern (coun- 
terclockwise in the sound), and 4) the coastal topography], the most extensive tidal flats in Japan, exposed for a maximum of 6-7 km offshore, have been developed along the eastern to the northwestern coastline, i.e., from the base of Uto Peninsula (the mouth of the Midori River) to Isahaya Bay (Fig. 7). The total area of the intertidal flats is estimated to range from $110 \mathrm{~km}^{2}$ at neap tides to $240 \mathrm{~km}^{2}$ at spring tides. By contrast, along the other coastline of the sound (i.e., around the tip of Uto Peninsula, Ôyano Island, Amakusa-Kamishima Island, AmakusaShimoshima Island, and Shimabara Peninsula) and the coastlines of Tachibana Bay and the East China Sea are scattered much smaller intertidal sandflats, mudflats, and sandy beaches. These intertidal flats and beaches are separated by rocky shores, comprising cliffs, boulder-, cobble-, and shingle-beaches, and besides, there are man-made constructions such as harbors and penaeid shrimp ponds.

Figure 7 also shows the distribution of median phi $(\mathrm{Md} \varnothing)$ values of the sediments (between 5 and $20 \mathrm{~cm}$ below the substrate surface) from 26 stations on the intertidal flats along the coast from Isahaya Bay to Uto Peninsula in Ariake Sound [clockwise from Stn 1 to Stn 26 (CORC, OSJ, 1985)]. The first 25 stations are located within the extensive mud- or sandflats, only Stn 26 (= Stn 25 in Fig. 8) being on a small sandflat near the tip of Uto Peninsula. Of the extensive tidal flats, those along Isahaya Bay and the northern coast of Ariake Sound are the mudflats, composed of fine silts with 6.5-8.0 median phi (Stns 1-15); in particular, along the northwestern coast from Stn 3 to Stn 7, mud is heterogeneous from place to place, mixed with small boulders, cobbles, and shingle. In contrast, along the southern half of the eastern coast of Ariake Sound, medium fine sands with 1.6-3.0 median phi are predominant (Stns 16-25), except for

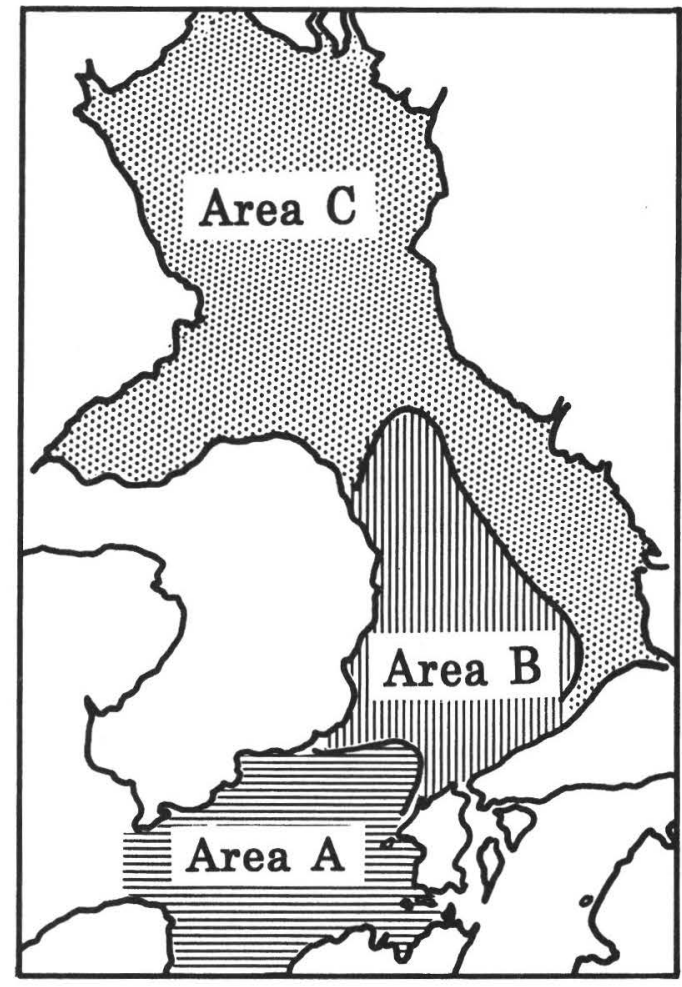

Fig. 6. Subdivision of the Ariake Sound waters according to NPIF's (1956) scheme: Area A = the open-sea water regime; Area $\mathrm{B}=$ the mixed-water regime; and Area $\mathrm{C}=$ the coastalwater regime. Adapted from Fig. 1-17 in NPIF (1956).

coarse - medium silts (4.4-6.3 median phi) localized just in front of the mouths of two large rivers (Stns 22 and 23). The sediment from Stn 26 is medium sand (1.2 median phi). As to the median phi of sediments (within $3 \mathrm{~cm}$ from the substrate surface) of the smaller tidal flats and beaches other than the above, those values for 14 stations in Fig. 8 have been obtained, as follows (only sandflats or sandy beaches were considered because no individuals of Nihonotrypaea were found on mudflats, as shown later): Stns 1, 3, and 37 (for the East China Sea); Stns 6 and 35 (for Tachibana Bay); and Stns 12, 13, 15, 17, 26, 27, 30, 31, and 34 (for Ariake Sound). The data for Stn 1, Stn 31, and 


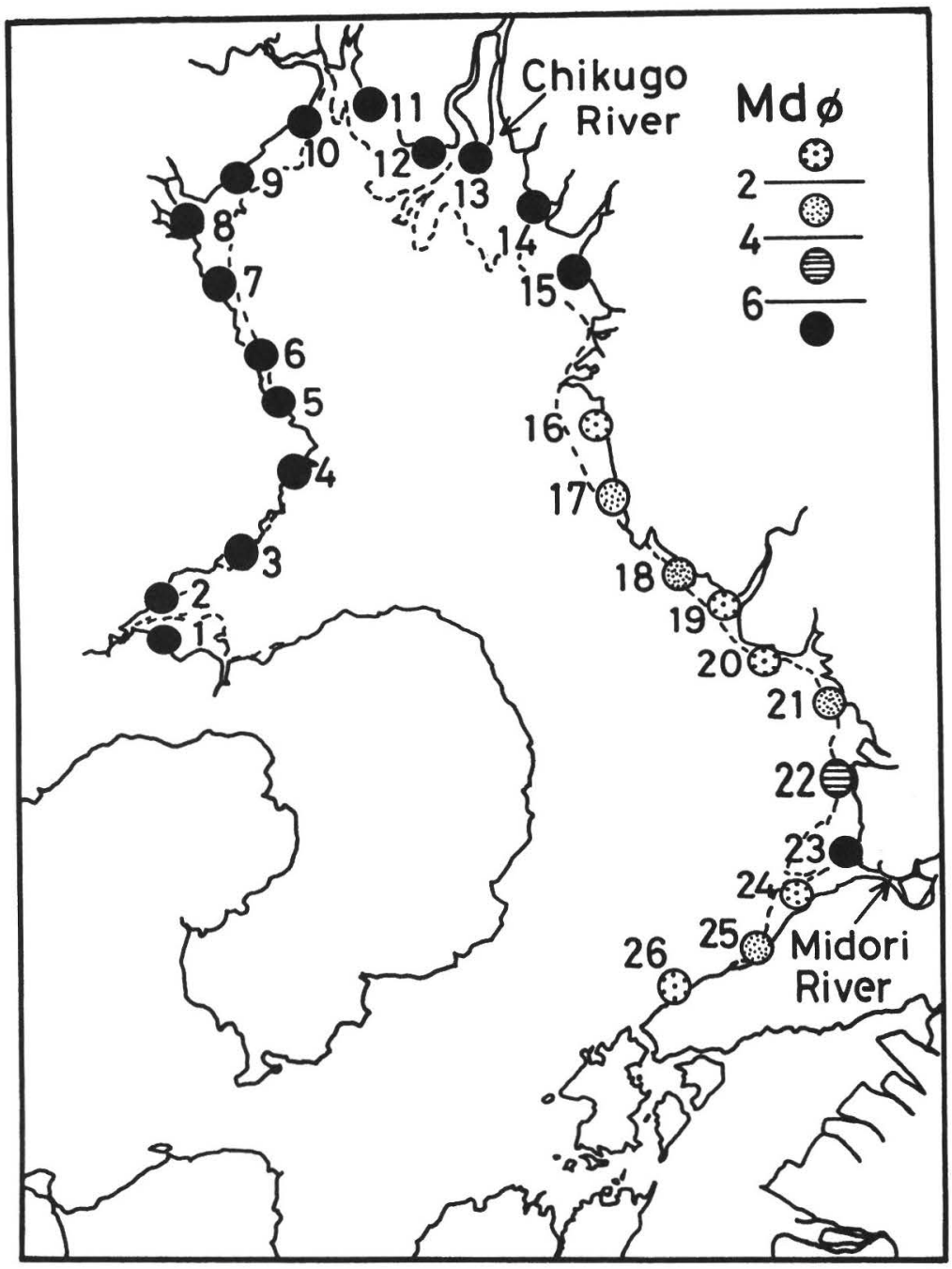

Fig. 7. Distribution of the four categories of phi median diameter (Md $\varnothing$ ) values of the sediments from the 26 stations (Stns 1-26) of the intertidal flats along the coastline from Isahaya Bay to Uto Peninsula in Ariake Sound. The broken line along the coastline indicates the maximum extent of the extensive tidal flats. Adapted from Fig. 13 of Part I in CORC, OSJ (1985), with the permission of the publisher.

Stn 35 are from Noichi et al. (1990), Kosuge et al. (1994), and Tamaki \& Suzukawa (1991), respectively, and the granulometric analysis of the sediments from the other 11 stations was conducted in the present study according to Buchanan (1984). The sediments at the 14 stations are medium - fine sands with 1.3-2.7 median phi.
Sampling of three species of Nihonotrypaea

To collect specimens of the three Nihonotrypaea species or check their presence or absence in intertidal habitats along the target coastline (Fig. 2), the sampling was carried out during March, 1993 to June, 1999. A total of 103 locations and a total of 26 locations were visited for intertidal flats and sandy beaches 
(expected habitats for $N$. harmandi and $N$. japonica) and for boulder beaches (expected habitats for $N$. petalura), respectively, during low spring tides (Fig. 8). For the mudflats, whether extensive or not, the sampling was restricted to the areas close to the land because it was impossible to walk for a long distance offshore through mud. By contrast, almost the entire area of each of the smaller sandflats, sandy beaches, and boulder beaches was surveyed. Even for several extensive sandflats in Ariake Sound, it was possible to reach the lower tidal zone by way of concrete roads constructed to facilitate clamming and laver culture or by the use of a boat while the sandflats were submerged (e.g., Stns 18, 20, 21, and 22). At each location (hereafter called a station), several points for the sampling were determined by making an effort to detect the burrow openings on the substrate surface, which were expected to be inhabited by ghost shrimps. For intertidal flats and sandy beaches, a cylindrical corer (100 $\mathrm{cm}^{2}$ x $100 \mathrm{~cm}$ long acrylic tube) and/or a yabby pump (18 $\mathrm{cm}^{2}$ x $77 \mathrm{~cm}$ length) were used to collect shrimps. The corer was pushed into the sediment as deep as possible (up to $70-80 \mathrm{~cm}$ ). At least 10 sediment columns were extracted and the shrimps collected. At 38 of the total 103 stations, collected shrimps were fixed with $10 \%$ neutralized formalin solution for the identification to the species level. At the other stations, only the presence or absence of shrimps was recorded in the field without species' identification. For boulder beaches, shrimps were collected by excavating sand between boulders by hand (Fig. 1b); the use of a corer or a yabby pump was ineffective for such small sand patches of shallow depth under which boulders often lay. All the collected shrimps were preserved. For this kind of microhabitat, it is difficult to assess the absolute densities of shrimps because rather a limited number of shrimps, corresponding to surface burrow-openings, were successfully caught. To evaluate a relative abundance of shrimps for each boulder beach, the ratio of the total number of shrimps to the summed time necessary for their collection (if two or more persons were involved, their totals were considered for the 'sampling effort') was calculated.

\section{Results}

Figure 8 shows the distributions of the three species along the target coastline at the 103 stations for $N$. harmandi and $N$. japonica and at the 27 stations for $N$. petalura [the 26 stations visited in the present study plus Konishi et al.'s (1990) study site]. As expected, $N$. petalura occurred only on boulder beaches, in which neither $N$. harmandi nor $N$. japonica were collected. It was also revealed that $N$. harmandi and $N$. japonica were essentially tidal-flat and/or sandy-beach inhabitants. Table 1 lists the percentages of $N$. harmandi and $N$. japonica at the 38 selected stations designated as the solid/ blank/half-and-half circles with serial numbers in Fig. 8. Table 2 lists the abundance data for $N$. petalura at the 15 stations where it occurred, which were designated as double circles with small alphabet letters in Fig. 8.

Nihonotrypaea harmandi was distributed along the coast of the East China Sea (Stns 1-5 and Stns 36-38), Tachibana Bay (Stns 6-11 and Stn 35), and the outermost (= toward Hayasaki Inlet) one third part of Ariake Sound (Stns 12-14 and Stns 24-34 except Stn 29). Except for three stations (Stns 13, 26, and 28), only this species occurred at these stations. The line connecting Stn 14 and Stn 24, which delimits the innermost distribution of $N$. harmandi in Ariake Sound, accords fairly well with the inner limit of the open-sea water regime (Area A) in Fig. 6. In its distribution range, $N$. harmandi in- 


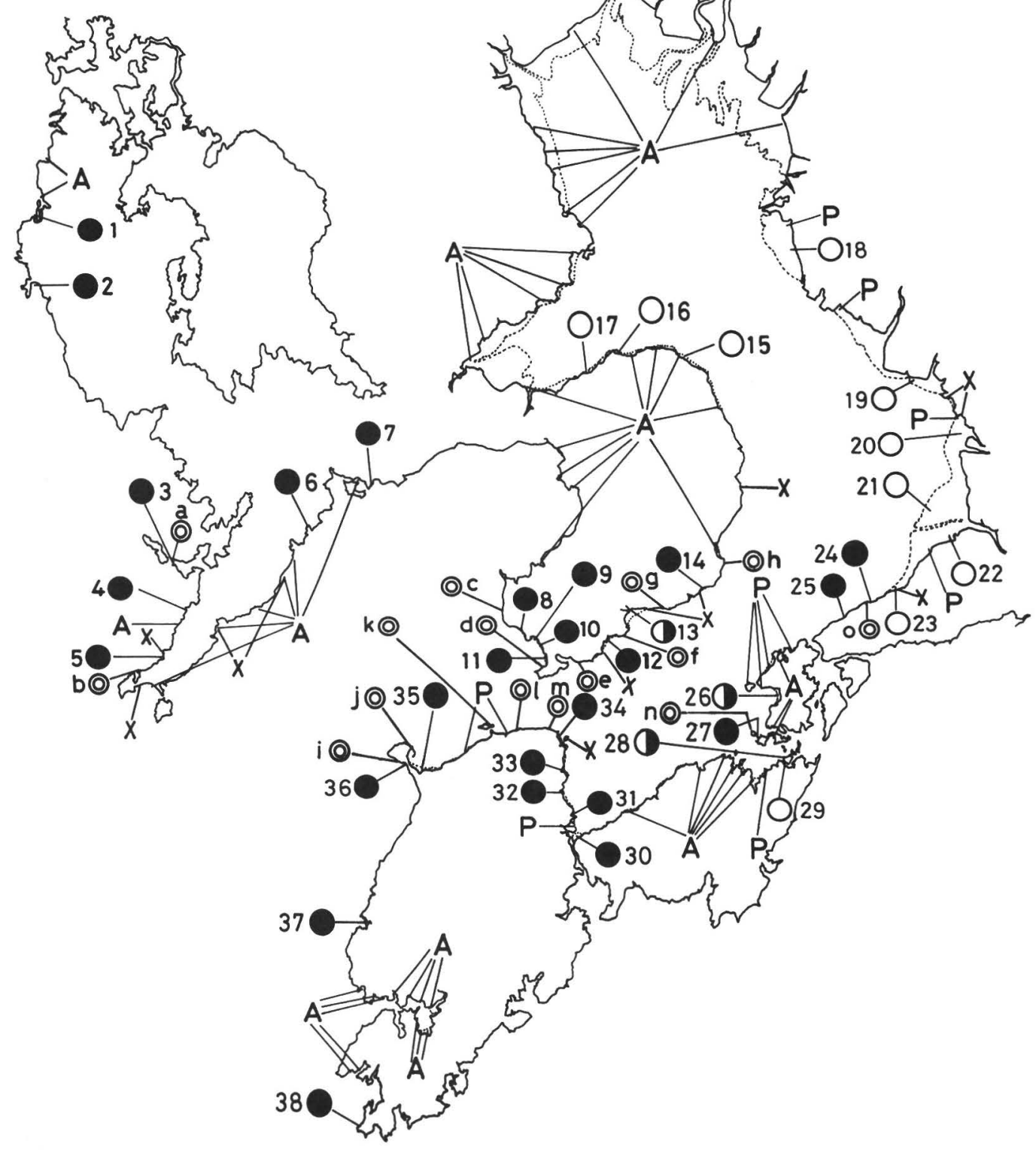

Fig. 8. Distributions of Nihonotrypaea harmandi and N. japonica at 103 locations and N. petalura at 27 locations along the coastline from Ariake Sound through Tachibana Bay to the East China Sea (Fig. 2). From the 38 selected stations (designated as serial station numbers) of the former locations and all stations (designated as small alphabet letters) of the latter locations, the specimens were brought back to the laboratory for the identification to the species level and the enumeration of ghost shrimp numbers (Tables 1 and 2). The meanings of the symbols are, as follows: solid circles - only $N$. harmandi present; open circles - only $N$. japonica present; halfand-half circles - both $N$. harmandi and $N$. japonica present; $\mathrm{P}$ - only confirmation of the presence of ghost shrimps on tidal flats and sandy beaches without species' identification; A - ghost shrimps absent on tidal flats and sandy beaches; double circles - only $N$. petalura present; and crosses - ghost shrimps absent on boulder beaches. The dotted line offshore of the coastline indicates the maximum extent of the extensive intertidal flats in Ariake Sound and of the other relatively large tidal flats in the sound and Tachibana Bay. 
habited almost all the protected sandflats and several exposed, sandy beaches. Within the exposed sandy beaches, such as located along the coast facing the East China Sea (Stns 4 and 5 and Stns 36-38), the distribution of the shrimp was restricted to microhabitats behind some kind of shelter, whether natural or artificial. Either mudflats or beaches composed of boulders, cobbles, and shingle appeared unsuitable for the species to inhabit. This would be the main reason that the species was absent from 1) most of the western coasts of the target coastline, facing the East China Sea, 2) most of the coast facing northern Tachibana Bay, and 3) a large part of the coast of AmakusaKamishima Island. Of the local populations in the East China Sea and Tachibana Bay, the population size of the Tomioka Bay sandflat (Stn 35) was by far the largest in terms of both the dimension of the sandflat (150-700 $\mathrm{m}$ along the tidal gradient $\mathrm{x} 4000 \mathrm{~m}$ alongshore) and the density of the population (500-1300 adult shrimps $/ \mathrm{m}^{2}$ ) occupying almost the entire sandflat (Tamaki et al., 1997). In Ariake Sound, several sandflats (e.g., Stn 13, Stn 30, and Stn 'P' between Stn 30 and Stn 31) are large, comparable to the Tomioka Bay sandflat, but the lower-density shrimp population was not widespread at each location. Thus the population size of the Tomioka Bay sandflat appeared to be the largest over its entire distribution range in this estuarine system.

The main habitats of $N$. japonica were the extensive sandflats developed along the eastern coast of Ariake Sound (Stns 18-23) and the less extensive sandflats along the northern coast of Shimabara Peninsula (Stns 15-17). At these stations, this species occurred exclusively. Nihonotrypaea japonica was absent from the extensive mudflats on the northern coast of Ariake Sound and Isahaya Bay. Along the coast of Uto Peninsula, the boundary between the distributions of $N$. japonica and $N$. harmandi was obvious, with the southern distribution limit of the former being at the edge of the extensive sandflat (Stn 23) and the northern distribution limit of the latter being on a small sandflat (Stn 24), respectively. Both species occurred at three stations located around the boundary between Area Aand Area B-water regimes (Fig. 6). Nihonotrypaea japonica was subordinate at the two stations (Stns 13 and 26), while it was dominant at the other station (Stn 28) (Table 1). At Stn 29, which is close to Stn 28 , the occurrence of $N$. japonica was exclusive. Stns 13 and 26 belong to the larger-sized sandflats as compared with those positioned by Stns 28 and 29. At Stn 13 , half the number $(=2)$ of the $N$. japonica specimens was collected from a muddy-sand substrate containing bivalve shells, cobbles, and shingle at the mouth of a local river, which is relatively large among the small rivers distributed along the eastern coast of Shimabara Peninsula. Similar substrate conditions were noted in relation to the occurrence of $N$. japonica at Stns 28 and 29, with the inpouring of small freshwater streams in this case. Nihonotrypaea harmandi was never found in such kinds of microhabitats.

The time for the collection of $N$. petalura ('sampling effort') at each station ranged from 30 to $240 \mathrm{~min}$. The distribution range of $N$. petalura in this estuarine system was identical to that of $N$. harmandi, although a large part of the coast facing the East China Sea has not been visited for the collection of the former species. At Stn h in Fig. 8, only a single shrimp was collected during 150 min (Table 2) and no shrimps during 75 min at the cross-mark station just north of Stn h. On the extensive sandflat stretching northward from Stn 23 in Ariake Sound, in which $N$. japonica resides, only a few boulder patches (only at the highest tidal zone) were available for a potential habitat of $N$. petalura. Actually no shrimps were collected there (the 
Table 1. Total number of the collected specimens $(n)$ of Nihonotrypaea harmandi and $N$. japonica and the percentage of $N$. harmandi at the 38 selected stations along the target coastline in western Kyushu, Japan (the stations with serial numbers in Fig. 8). The meanings of the symbols are: $+=100 \% ;-=0 \%(=100 \%$ N. japonica $)$; and $*=11872$ on the Tomioka Bay sandflat (after Tamaki et al., 1997).

\begin{tabular}{rrcrrc}
\hline \hline Stn & $n$ & \%harmandi & Stn & $n$ & \%harmandi \\
\hline 1 & 30 & + & 20 & 36 & - \\
2 & 2 & + & 21 & 25 & - \\
3 & 41 & + & 22 & 204 & - \\
4 & 4 & + & 23 & 39 & - \\
5 & 1 & + & 24 & 29 & + \\
6 & 37 & + & 25 & 27 & + \\
7 & 2 & + & 26 & 109 & 98.2 \\
8 & 1 & + & 27 & 79 & + \\
9 & 52 & + & 28 & 15 & 6.7 \\
10 & 6 & + & 29 & 6 & - \\
11 & 4 & + & 30 & 41 & + \\
12 & 46 & + & 31 & 2 & + \\
13 & 217 & 98.2 & 32 & 4 & + \\
14 & 26 & + & 33 & 6 & + \\
15 & 9 & - & 34 & 86 & + \\
16 & 2 & - & 35 & $*$ & + \\
17 & 2 & - & 36 & 23 & + \\
18 & 41 & - & 37 & 52 & + \\
19 & 1 & - & 38 & 1 & + \\
\hline
\end{tabular}

three cross marks in Fig. 8). The relative abundance of shrimps was by far the highest on the northern coast of Amakusa-Shimoshima Island (Table 2; Stns j-m), followed by four stations around the southern end of Shimabara Peninsula (Stns c-f) and one peculiar station on Uto Peninsula (Stn o). As to the microhabitat conditions, the preferred substrate for $N$. petalura appeared to be coarse - medium sand surrounded by boulders (Fig. 1). However, on the stronger wave-swept beaches, predominated by the larger-sized boulders, no shrimps were collected.

\section{Discussion}

In the present study, it was demonstrated that the distribution range of $(N$. harmandi $+N$. petalura) and that of $N$. japonica were clearly separated along the salinity gradient from Ariake Sound to the East China Sea. The boundary be- tween the major habitats of ( $N$. harmandi $+N$. petalura) and N. japonica in Ariake Sound was situated around the inner limit of the open-sea water regime (Area A in Fig. 6). In the light of long-term-averaged salinity (psu) values in the surface waters in the rainy season, ( $N$. harmandi $+N$. petalura) and $N$. japonica occurred in the ranges of 34.0-30.5 [the East China Sea + Tachibana Bay + the outermost one third part of Ariake Sound (= Area A = the open-sea water regime)] and 30.5-28.5 (mainly the middle one third part of Ariake Sound), respectively (Figs. 3, 6, and 8). Using the Venice-system terms for the classification of brackish waters, $N$. harmandi and $N$. petalura can be designated as euhaline to mixo-euhaline species, while $N$. japonica as a mixopolyhaline species. The more reduced size of corneas in $N$. japonica than in $N$. harmandi (see Manning \& Tamaki, 1998) might be related to the more turbid wa- 
Table 2. Total number of the collected specimens ( $n$ ) of Nihonotrypaea petalura, the time necessary for their collection ( $\mathrm{t})$, and the relative shrimp abundance $(n / \mathrm{t})$ at the 15 stations along the target coastline in western Kyushu, Japan (the stations with small alphabet letters in Fig. 8). Bars mean no data available for Stn $n$ (only the presence of the shrimp is recorded in Konishi et al., 1990).

\begin{tabular}{crrl}
\hline \hline Stn & $n$ & $\mathrm{t}(\min )$ & $n / \mathrm{t}(\mathrm{min})$ \\
\hline $\mathrm{a}$ & 3 & 122 & 0.025 \\
$\mathrm{~b}$ & 9 & 150 & 0.060 \\
$\mathrm{c}$ & 6 & 60 & 0.100 \\
$\mathrm{~d}$ & 4 & 75 & 0.053 \\
$\mathrm{e}$ & 10 & 100 & 0.100 \\
$\mathrm{f}$ & 7 & 120 & 0.058 \\
$\mathrm{~g}$ & 3 & 120 & 0.025 \\
$\mathrm{~h}$ & 1 & 150 & 0.007 \\
$\mathrm{i}$ & 11 & 240 & 0.046 \\
$\mathrm{j}$ & 60 & 150 & 0.400 \\
$\mathrm{k}$ & 50 & 90 & 0.556 \\
$\mathrm{l}$ & 36 & 90 & 0.400 \\
$\mathrm{~m}$ & 9 & 40 & - \\
$\mathrm{n}$ & - & - & 0.144 \\
$\mathrm{o}$ & 23 & 160 & \\
\hline
\end{tabular}

ters which the former species occupies (Fig. 5). From the viewpoint of the dimension and substrate conditions, the habitats for the three species can be basically characterized, as follows: 1) $N$. harmandi -the relatively small sandflats and sandy beaches of medium - fine sands, with boulder beaches, very exposed sandy beaches, and mudflats uninhabited; 2) $N$. petalura - small sand patches surrounded by boulders in boulder beaches; and 3) $N$. japonica - the extensive sandflats of medium - fine sands, with boulder beaches, exposed sandy beaches, and mudflats uninhabited. Table 1 in Sakai (1969), which lists the localities of the specimens (his Callianassa japonica) examined from the Japanese waters, includes various habitat types ranging from estuaries to the open sea. These localities include the Arao sandflat in Ariake Sound (= Stn 18 in Fig. 8: N. japonica) and 'Higashihama' beach in Tachibana Bay (= the Tomioka Bay sandflat $=$ Stn 35 in Fig. 8: N. harmandi).

The distributions of the three
Nihonotrypaea species along the coastline in this estuarine system would primarily be determined by physiological adaptation of adults to their local habitat conditions. For example, it is anticipated that adults of $N$. japonica should have both higher osmoregulatory ability against fluctuating salinity and higher thermal tolerance against the larger-amplitude change in temperature. Interestingly, at three of the four locations with smaller sandflats where $N$. japonica occurred outside the extensive sandflats in Ariake Sound (i.e., Stns 13, 28, and 29 in Fig. 8), most of the shrimps were collected from the microhabitats under the influence of local freshwater flows. It is also anticipated that adults of $N$. japonica should have higher tolerance against lower oxygen tension of its burrow waters because the duration of exposure of the extensive tidal flats inhabited by the shrimp is much longer. In their paper on the burrow architectures of $N$. japonica and $N$. harmandi, Tamaki \& Ueno (1998) predicted that water stagnation and oxygen 
deficiency could more easily occur in the $N$. japonica's burrow with a single surface opening than in the $N$. harmandi's Yshaped burrow with two surface openings. Thus, to elucidate the mechanisms in determining the distribution patterns of the three species, future ecophysiological studies of adult shrimps will be required.

We suggest that the distribution limits of the three Nihonotrypaea species is also determined by the extent of dispersal and/ or retention of their larvae in relation to adult habitats. Such larval dynamics involve both physical oceanographic and physiological aspects. In this respect, studies by Hirota $(1974,1977,1979)$ on the distribution of zooplankton in Ariake Sound, especially that of copepods, seem relevant to the findings of the present study. He detected a clear pattern in the distributions of the 'oceanic' and 'estuarine' zooplankton species, their boundary being around the inner limit of Area A (Fig. 6). Specifically in the present study, questions arise about 1$)$ how larvae of $(N$. harmandi $+N$. petalura) are retained for the maintenance of the largest populations on the northern coast of AmakusaShimoshima Island, 2) how larvae of $N$. japonica are retained within Ariake Sound, and 3) how physiological stresses are exerted on $(N$. harmandi $+N$. petalura) larvae and $N$. japonica larvae by the estuarine waters and the open-sea waters, respectively. Future field and laboratory studies will also be needed to determine the distribution patterns of larvae of the three species in the entire area.

\section{Acknowledgments}

We thank H. Tanoue, Y. Mizuta, Y. Fukuda, K. Tamaki, H. Ueno, T. Hasegawa, H. Kimura, S. Miyabe, K. Hayashi, R. Hirohashi, Y. Watabe, and Y. Wardiatno for their help with the field work and the staff of Amakusa Marine
Biological Laboratory, Kyushu University and Aitsu Marine Biological Laboratory, Kumamoto University for providing facilities. The grain-size analysis of sediments was conducted by M. Taka and $\mathrm{H}$. Kimura. Valuable information on the distribution of $N$. japonica was provided by Messrs. M. Hirata and I. Hirayama. Mr. N. Kosuge (Tokai University Press) gave us permission to reproduce the figures. The manuscript was improved by comments of Dr. K. Baba and two referees. This study was partly supported by The Ministry of Education, Science, Sports and Culture Grants-in-Aid for Scientific Research on Priority Areas (No. 319), 'Symbiotic biosphere: an ecological interaction network promoting the coexistence of many species' and (C) \# 09640754 to A.T.

\section{Literature Cited}

Buchanan, J. B., 1984. Chapter 3: Sediment analysis. In: N. A. Holme and A. D. McIntyre, (eds.), Methods for the study of marine benthos. xii +387 pp., Blackwell, Oxford, 41-65.

Coastal Oceanography Research Committee, The Oceanographical Society of Japan, 1985. Chapter 21: Ariake-Kai. In: Coastal Oceanography of Japanese Islands. xxvi + 1106 pp., Tokai University Press, Tokyo, 815-878. (In Japanese)

, 1990. Chapter 33: Coastal area around the Goto archipelagos. In: Coastal Oceanography of Japanese Islands, Supplementary Volume. xxii + 839 pp., Tokai University Press, Tokyo, 669-737. (In Japanese)

Hirota, R., 1974. Occurrence of zooplankton in Ariake-Kai, western Kyushu, I. Regional occurrence of the important zooplankton in the warmer season. Kumamoto Journal of Science, Biology, 12: 1-15.

- 1977. Occurrence of zooplankton in Ariake-Kai, western Kyushu, II. Occurrence of oceanic copepods in autumn. Kumamoto Journal of Science, Biology, 13: 43-48.

, 1979. Occurrence of zooplankton in Ariake-Kai, western Kyushu, III. Regional occurrence of the important zooplankton in the colder season. Kumamoto Journal of Science, Biology, 14: 33-41. 
Konishi, K., Quintana, R. R., \& Fukuda, Y., 1990. A complete description of larval stages of the ghost shrimp Callianassa petalura Stimpson (Crustacea: Thalassinidea: Callianassidae) under laboratory conditions. Bulletin of National Research Institute of Aquaculture, Nansei, Japan, 17: 27-49.

Kosuge, T., Nishihama, S., \& Takayama, J., 1994. Macrobenthos at Mogine sand flat, Amakusa, Kyushu, with special reference to the occurrence of the two molluscs, Umbonium moniliferum (Lamarck) and Meretrix lusoria (Röding). Nankiseibutu: The Nanki Biological Society, 36: 115-119. (In Japanese, with English abstract)

Manning, R. B., \& Tamaki, A., 1998. A new genus of ghost shrimp from Japan (Crustacea: Decapoda: Callianassidae). Proceedings of the Biological Society of Washington, 111: 889-892.

Matsuno, T., Shigeoka, M., Tamaki, A., Nagata, T., \& Nishimura, K., 1999. Distributions of water masses and currents in Tachibana Bay, west of Ari-ake Sound, Kyushu, Japan. Journal of Oceanography, 55: 515-529.

Nagasaki Prefectural Institute of Fisheries, 1956. Investigation of Ariake-Kai No. 6. Nagasaki Prefectural Institute of Fisheries Data Series, 89: 58-117. (In Japanese)

Noichi, T., Kanbara, T., Mito, T., Sakamoto, F., Kimura, M., \& Senta, T., 1990. Occurrence and ecology of juvenile striped jewfish Stereolepis doederleini (Family Percichthyidae) in Yanagihama Beach, Nagasaki Prefecture. Bulletin of the Faculty of Fisheries, Nagasaki University, 68: 29-34. (In Japanese, with English abstract)

Raffaelli, D., \& Hawkins, S., 1996. Intertidal Ecology. $x+356$ pp., Chapman \& Hall,
London.

Sakai, K., 1969. Revision of Japanese callianassids based on the variations of larger cheliped in Callianassa petalura Stimpson and $C$. japonica Ortmann (Decapoda: Anomura). Publications of the Seto Marine Biological Laboratory, 17: 209-252, pls. 9-15.

Seikai National Fisheries Research Institute, 1970. Report on the Investigation of the Coastal Oceanography and the Distribution of Fish Schools in Tachibana Bay: a Model System. 157 pp., Seikai National Fisheries Research Institute, Nagasaki. (In Japanese)

Tamaki, A., Ingole, B., Ikebe, K., Muramatsu, K., Taka, M., \& Tanaka, M., 1997. Life history of the ghost shrimp, Callianassa japonica Ortmann (Decapoda: Thalassinidea), on an intertidal sandflat in western Kyushu, Japan. Journal of Experimental Marine Biology and Ecology, 210: 223-250.

— \& Suzukawa, K., 1991. Co-occurrence of the cirolanid isopod Eurydice nipponica Bruce \& Jones and the ghost shrimp Callianassa japonica Ortmann on an intertidal sand flat. Ecological Research, 6: 87100.

-, \& Ueno, H., 1998. Burrow morphology of two callianassid shrimps, Callianassa japonica Ortmann, 1891 and Callianassa sp. (= C. japonica: de Man, 1928) (Decapoda: Thalassinidea). Crustacean Research, 27: 28-39.

Address: Faculty of Fisheries, Nagasaki University, Bunkyo-machi 1-14, Nagasaki 852-8521, Japan

E-mail: (AT) tamaki@net.nagasaki-u.ac.jp 